\title{
Fortified fertilizer application in wheat (Triticum aestivum L.) grown under water stress condition
}

\author{
Anser $\mathrm{Ali}^{1 *}$, Muhammad Tariq ${ }^{1}$, Muhammad Rashid ${ }^{2}$, Shahmir Ali \\ Kalhoro $^{2}$, Mudassar Maqbool ${ }^{1}$, Muneer Ahmed ${ }^{2}$, Mehr-un-Nisa Narejo ${ }^{3}$ \\ and Farooq Ahmed Marri ${ }^{2}$ \\ 1. Department of Agronomy, Ghazi University, D. G. Khan-Pakistan \\ 2. Faculty of Agriculture, Lasbela University of Agriculture, Water and Marine Sciences, Uthal-Pakistan \\ 3. Faculty of Crop Production, Sindh Agriculture University, Tandojam, Pakistan \\ *Corresponding author's email: uafanser@gmail.com \\ Citation \\ Anser Ali, Muhammad Tariq, Muhammad Rashid, Shahmir Ali Kalhoro, Mudassar Maqbool, Muneer Ahmed, \\ Mehr-un-Nisa and Farooq Ahmed, Marri. Fortified fertilizer application in wheat (Triticum aestivum L.) grown \\ under water stress condition. Pure and Applied Biology. Vol. 8, Issue 1, pp960-967. \\ http://dx.doi.org/10.19045/bspab.2019.80037
}

\begin{tabular}{llll}
\hline \hline Received: 07/12/2018 & Revised: 08/03/2019 & Accepted: 11/03/2019 & Online First: 28/03/2019 \\
\hline \hline
\end{tabular}

\section{Abstract}

Water stress is a major threat against wheat growth. The effects of induced stress can be reduced after by fortified fertilizer treated by Plant Growth Promoting Bacteria (PGPB). With the objective to combat the water stress, two different experiments under net house and field condition were conducted. Three different states of fertilizer [ $\mathrm{F}_{0}$ : Control (no fertilizer application); $\mathrm{F}_{1}$ : PGPB-coated fertilizer (urea and phosphorous) \& $\mathrm{F}_{2}$ : uncoated fertilizer (urea and phosphorous)]. In a pot experiment, wheat plants were applied fertilizer in raised and wellwatered (60 percent of field capacity) and water stressed (40 percent of field capacity) conditions in soil filled pots. In experiment-II (field study), similar treatments of fertilizer were revised, but well-watered and water stress treatments/plots were irrigated for 60 seconds and 30 seconds respectively. At maturity plants were harvested and various morphological (number of tillers/plant, number of spikelet/spike, number of grains/spike, weight of grains, biological yield, economic yield and harvest index) and biochemical parameters (leaf nitrogen, phosphorous \& potassium contents) of crop were recorded. Leaf chlorophyll and relative water contents of crop were also measured 60 days after sowing. In this study, it was demonstrated that the water stress adversely affected all the above mentioned parameters. The PGPB coated fertilizer application in wheat significantly increased ( $\mathrm{p}<0.01$ for pot and $\mathrm{p}<0.05$ for field study) morphological and biochemical parameters in the presence and absence of water stress both under net house and field conditions. We can conclude from these findings that application of PGPB coated fertilizer is valuable strategy to mitigate the water stress impact on wheat with improved yield.

Keywords: Coated fertilizer; Un-coated fertilizer; PGPB; Chlorophyll; Harvest index 


\section{Introduction}

Sustainable crop production mainly depends upon water harvested from different sources. Water is becoming limiting source due to increase in population and aridity causing disastrous effect on agriculture sector and its productivity [1]. It is a common feature of less or erratic rainfall areas [2] and according to an estimate drought causes about $50 \%$ reduction in yield [3]. Water deficiency causes reduction of photosynthetic activity, denaturing of protein and production of reactive oxygen species (ROS) $[4,5]$.

Wheat (Triticum aestivum L.) is an important and one of key sources of energy and protein in the human diet, which shares $35.5 \%$ of total food grain production next to rice, but has low yield potential. In areas where cropping systems are intensive, supplementing soil nutrients by use of chemical fertilizers has attained inevitable importance for obtaining optimum yield of crops [6]. However, their utilization efficiency remains low, due to losses through volatilization, denitrification, leaching and ultimately fixed with clay particle and become unavailable to crop plants [7].

Among various techniques, exogenous application of silicon [6], potassium $\left(\mathrm{K}^{+}\right)$, salicylic acid (SA), glycinebetaine (GB) and proline as major organic osmolytes $[7,8]$ are believed to play a vital role against various a biotic and biotic stresses such as drought, salinity, extreme temperatures, UV radiation and heavy metals and pest attack. Previous studies show that this problem can be solved by the use of plant growth promoting bacteria (PGPB). Plants can be protected from the harmful effects of water stress [9].

Plant growth promoting rhizobacteria (PGPB) is the group of those bacteria which enhance the plant productivity and yield by number of direct and indirect mechanisms $[10,11]$. PGPB enhance plant's ability to establish themselves by bearing the the stressful conditions like water scarcity and nutrient limitations [12]. Prvious studies revealed that in cereal crops, PGPB play a vital role in various physiological procesees viz. increasing uptake of nitrogen, phosphorus and potassium in plant as well as chlorophyll content, enhance nodulation and nitrogen fixation \& acquisition of leaf relative water content of plants. $[13,14]$. PGPB are beneficial in increasing $\mathrm{N}$ fixation, P-solubilization and for the suppression of plant diseases. PGPB produce plant growth promoting compounds and improve the cycling of plant macro and micronutrients in water stress. They improve root morphology and increase surface area for water and nutrient uptake [15, 16]. PGPB also benefit associated plants through providing nutrition (nitrogen, phosphorous and iron), production of various beneficial plant hormones and enable plants to survive in a biotic stress $[\mathbf{1 7}, \mathbf{1 8}]$.

Keeping in view the significance of PGPB in plant growth promotion the present study has been planned with following objectives; i) to assess the role of PGPB-coated fertilizer application on wheat performance in the presence and absence of water stress ii) to know the impact of water stress on wheat crop iii) to compare the efficacy of PGPB-coated fertilizer application under net house \& field conditions.

\section{Materials and methods}

The current research was conducted in two different fashions simultaneously in net house (pot study) and field conditions to test the efficacy of fortified \{coated with plant growth promoting bacteria (PGPB)\} fertilizer application in wheat (Triticum aestivum L.) grown under well-water and water stress condition. To evaluate the effect of fortified fertilizer on wheat under water stress condition, the present experiments were conducted under well-watered and water stress conditions at Ghazi University, 
Dera Ghazi Khan, Pakistan (185 m above sea level, $31^{0}$ latitude North and $73^{\circ}$ longitude East) during fiscal year 2015-16. Experiment-I was conducted in plastic pots to evaluate the effect of fortified fertilizer application to mitigate the water stress in wheat. Three different states of fertilizers (coated, uncoated and without) were applied to investigate its effect on growth of wheat. In six pots, coated nitrogen \& phosphorus fertilizer (123-123 mg NP Kg${ }^{-1}$ of soil) was applied to check the role of PGPB (plant growth promoting bacteria). In other six pots same quantity of uncoated nitrogen \& phosphorus was applied to check its performance. Rests of the six pots were kept as control having no fertilizer. Contrasting water levels well-watered and water stress conditions were supplied in this experiment. In nine pots (three from each $\mathrm{F}_{0}, \mathrm{~F}_{\mathrm{c}} \& \mathrm{~F}_{\mathrm{uc}}$ ), water stress was applied by supplying water up to 40 percent of field capacity and rest of the nine pots were kept as well-watered by supplying water up to 60 percent of field capacity. Water application was maintained by weighing each pot after 3 to 4 day's interval throughout the growing season till maturity of plants. Locally manufactured digital balance was used for weighing of pots. It had weighing capacity in range from $200-30000 \pm 5 \mathrm{~g}$. Four $\mathrm{kg}$ of well-prepared soil was filled in each of 18 plastic pots. A basal dose of $\mathrm{K} @ 62 \mathrm{mg} \mathrm{Kg}^{-1}$ of soil as potassium sulphate was applied. All types of fertilizer were applied prior to seed sowing. In each pot 15 seed of local high yielding wheat variety Galaxy-2013 was sown which was thinned to 5 plants per pot after germination of seeds. Sowing was done on $8^{\text {th }}$ December, 2015. The pots were arranged according to factorial completely randomized design (CRD) with three replicates of each treatment.

Experiment-II was conducted simultaneously under well-watered and drought conditions. To evaluate the role of
PGPB three different states of fertilizer (coated, uncoated and without) were applied in wheat to investigate its role under water stress in field conditions. In six plots coated nitrogen \& phosphorus (120-100 kg NP ha-1) was applied to check the role of PGPB (plant growth promoting bacteria). In other six plots same dose of uncoated nitrogen \& phosphorus was applied. Rests of the six plots were used as control with no fertilizer. In nine plots water stress was applied by practicing to cut the water inflow in half time duration as compared to other nine well-watered plots. If a well-watered plot took sixty seconds to irrigate, the water stress plot was irrigated in 30 seconds. Seeds of local high yielding wheat variety Galaxy2013 were sown at the rate of $100 \mathrm{Kg} \mathrm{ha}^{-1}$ by maintaining $22.5 \mathrm{~cm}$ row $\mathrm{x}$ row distance. Sowing was done by using hand drill on $14^{\text {th }}$ December, 2015. Treatments mentioned below were applied in triplicate according to randomized complete block design (RCBD) with factorial fashion in $5 \times 2 \mathrm{~m}^{-2}$ net plot sizes. Total eighteen plots were prepared for this experiment. A basal dose of $60 \mathrm{Kg} \mathrm{ha}^{-1}$ of $\mathrm{K}$ potassium sulphate was applied. Complete dose of phosphorus, potassium and $1 / 2$ nitrogen was applied at sowing time. Remaining nitrogen was applied with first irrigation. At maturity plants were harvested and various morphological (number of tillers/plant, number of spikelet/spike, number of grains/spike, weight of grains, biological yield economic yield and harvest index) and biochemical parameters (leaf nitrogen contents, leaf phosphorous contents leaf potassium contents, leaf chlorophyll contents and leaf relative water contents) of crop were recorded in both experiments.

\section{Statistical analysis}

The collected data was analyzed statistically by using Fisher's analysis of variance (ANOVA) technique. Least Significant Difference (LSD) test was applied $(\mathrm{P}<0.01$ for pot and $\mathrm{P}<0.05$ for field study) to 
compare significant treatments means using Statistix version 8.1.

\section{Results}

Results of morphological parameters viz. number of tillers per plant, number of spikelet per spike, number of grains per spike, 100 grain weight $(\mathrm{g})$, economic yield (g plant $\left.{ }^{-1}\right)$, biological yield $\left(\mathrm{g} \mathrm{plant}^{-1}\right)$ and harvest index (\%) in pot study (Figure 1) and number of tillers $\mathrm{m}^{2}$, number of spikelet per spike, number of grains per spike, 1000 grain weight $(\mathrm{g})$, economic yield $\left(\mathrm{t} \mathrm{ha}^{-1}\right)$, biological yield $\left(\mathrm{t} \mathrm{ha}{ }^{-1}\right)$ and harvest index $(\%)$ in field study (Figure 2) showed that these were significantly $(\mathrm{P} \leq 0.01)$ reduced by water stress as compare to well-watered conditions. Coated fertilizer application improved the said parameters of both experiments in the presence of stress. Under well-watered condition, plants attained maximum morphological attributes in coated fertilizer followed by uncoated fertilizer application and lowest of these parameters were recorded in without fertilizer treatment. Similar trend was observed in water stress condition and maximum plant morphological characters were obtained in coated fertilizer followed by uncoated fertilizer application and lowest morphological parameters were recorded in without fertilizer treatment.

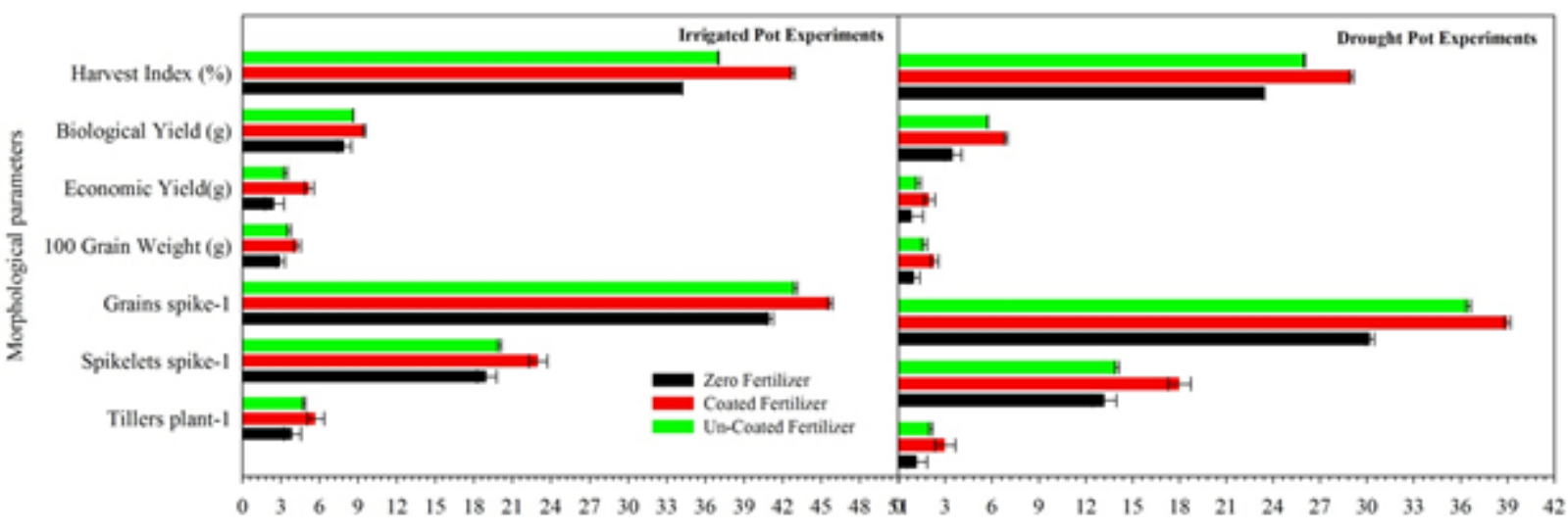

Figure 1. Effect of fortified fertilizers on morphological parameters of wheat plants in irrigated and drought stressed pot experiment. 


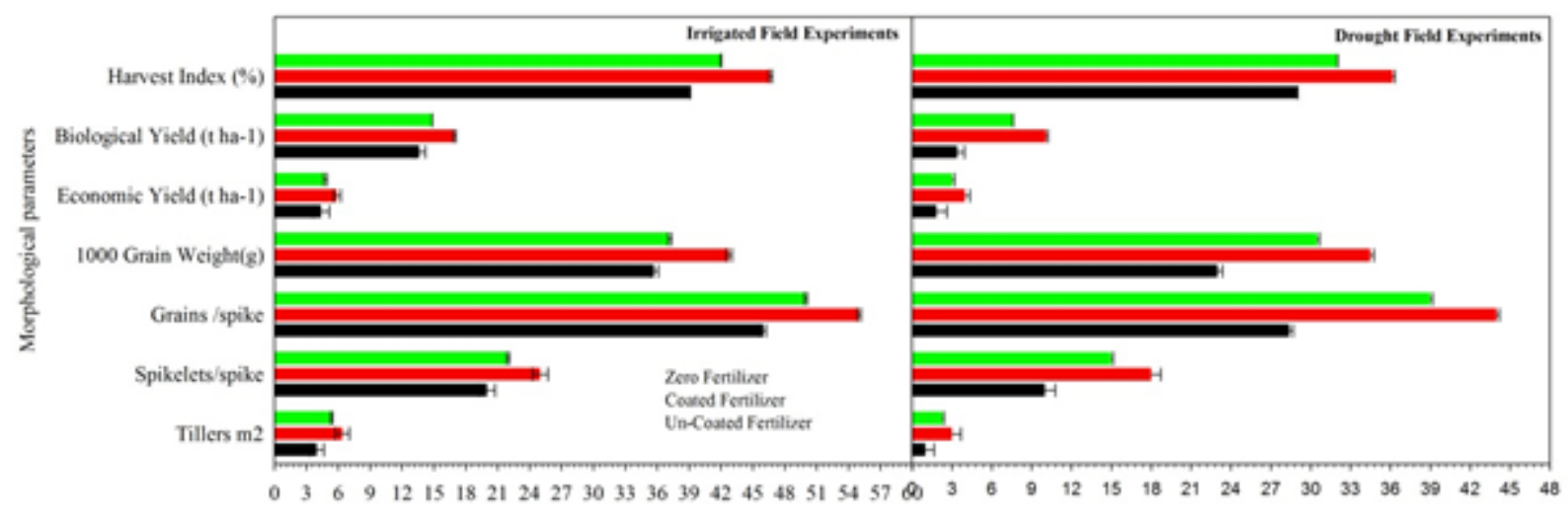

Figure 2. Effect of fortified fertilizers on morphological parameters of wheat plants in irrigated and drought stressed field experiment

Results of biochemical parameters such as leaf nitrogen content $\left(\mathrm{m} \mathrm{mol} \mathrm{g} \mathrm{g}^{-1} \mathrm{dwt}^{-1}\right)$, phosphorous content $\left(\mathrm{m}\right.$ mol g $\left.\mathrm{g}^{-1} \mathrm{dwt}^{-1}\right)$, potassium content (m mol $\left.\mathrm{g}^{-1} \mathrm{dwt}^{-1}\right)$, chlorophyll contents (SPAD Value) and relative water contents (\%) (Figure $3 \& 4$ ) showed that these were significantly $(\mathrm{P} \leq 0.01)$ reduced by water stress as compare to well-watered conditions. Coated fertilizer application improved the said parameters of both experiments in the presence of stress. Under well-watered condition, plants attained maximum biochemical attributes in coated fertilizer followed by uncoated fertilizer application and lowest of these parameters were recorded in without fertilizer treatment. Similar trend was observed in water stress condition and maximum plant biochemical characters were obtained in coated fertilizer followed by uncoated fertilizer application and lowest biochemical parameters were recorded in without fertilizer treatment.

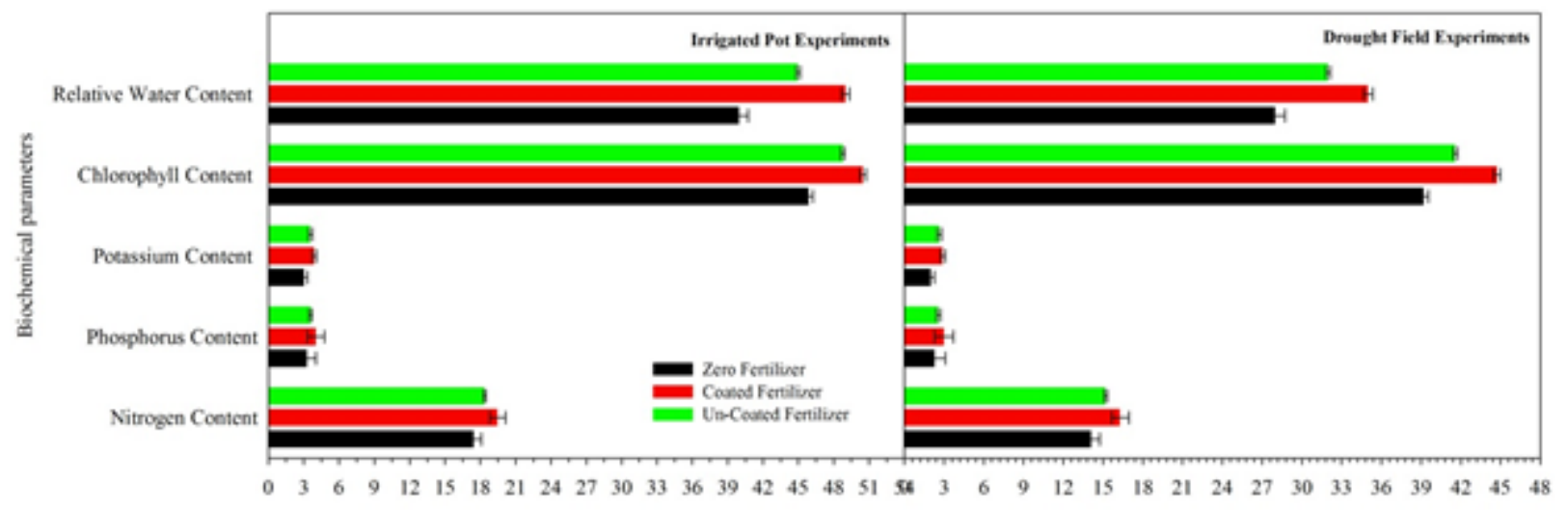

Figure 3. Effect of fortified fertilizers on biochemical parameters of wheat plants in irrigated and drought stressed pot experiment 


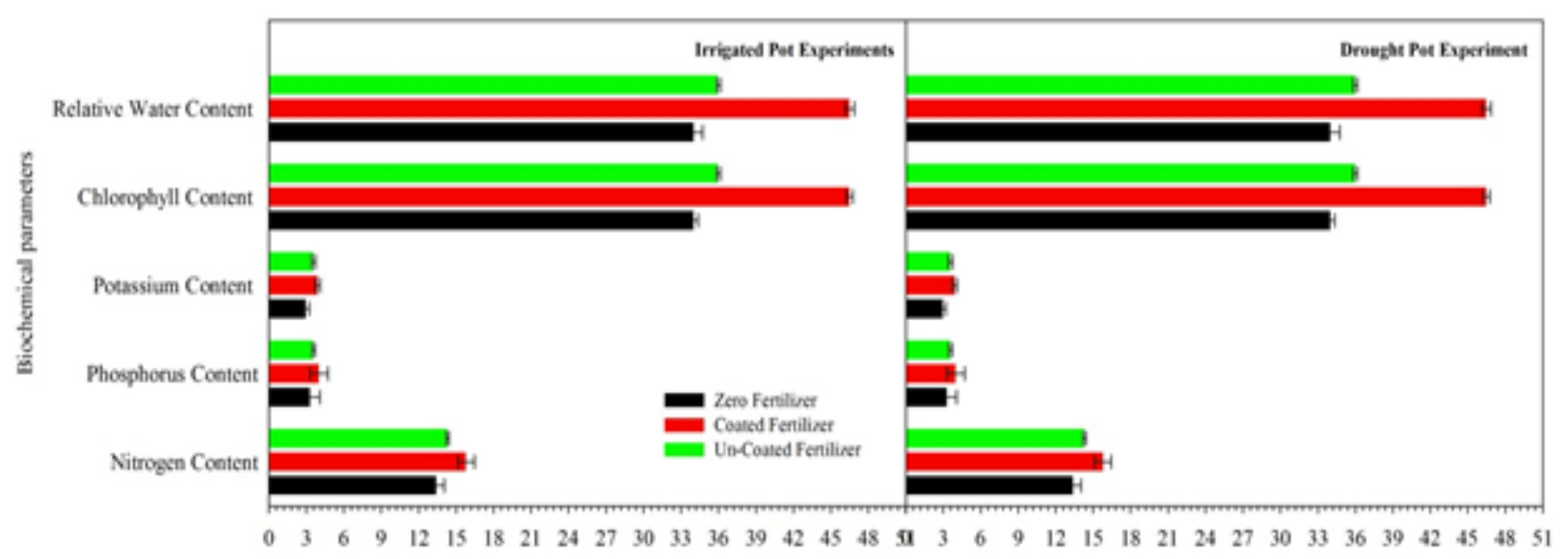

Figure 4. Effect of fortified fertilizers on biochemical parameters of wheat plants in irrigated and drought stressed field experiment

\section{Discussion}

The results of current study highlighted the role of plant growth promoting bacteria to cope the plants against water stress conditions. Application of PGPB coated fertilizer proved that it plays effective role in improving all the morphological and biochemical parameters of wheat plants. These parameters were significantly reduced under water stress condition in uncoated fertilizer application as well as in zero fertilizer. This reduction was due to the harmful effects of water stress on wheat plant. Water deficit Stress (Drought Stress) can result production of reactive oxygen species (ROS), disruption of water potential and denaturation of proteins and overall impact on crop productivity. Water stress conditions decrease plant productivity mainly due to decrease in cell turgidity and dehydration of protoplasm. Wyngaard \& Cabrera [17] reported that dehydration of protoplasm is directly related with reduced cell division.

Spike length, number of tillers plant ${ }^{-1}$, number of spikelets spike $^{-1}$, number of grains spike $^{-1}$ and grain weight play an important role towards final (economic and biological) yield. This important observation in present study can also be correlated with wheat yield that PGPB coated fertilizer improves the plant height. Economic and biological yield of wheat was drastically reduced in water stress condition. But results of this study depict that coated fertilizer application improve the final (economic and biological) yield of crop. This improvement was due to the beneficial role of PGPB to enhance plant growth by number of ways i.e. development of growth promoting hormones, uptake of essential nutrients and save the crop from diseases. PGPB produce the ACC-Deaminase enzyme that reduces the ethylene in the root of plants which enhance the root length and density so plants can easily uptake water and nutrients even in water deficit condition. The yield related results in my research correlates with the findings of Ali [6] that water stress affects length of spike, number of tillers plant ${ }^{-1}$, number of spikelets spike $^{-1}$, number of grains spike ${ }^{-1}$ and grain weight due to the hormonal imbalance (abscisic acid and cytokine) that decreases the growth due to change in cell wall extensibility. Plant breeders pay more attention to the number 
of grains per spike and grain weight while selecting the genotype for higher production. Current study proves that PGPB coated fertilizer application enhances crop production by improving number of grains and grain weight.

\section{Conclusion}

The coated fertilizer application showed significant improvement on biochemical (Leaf Nitrogen, Phosphorus and Potassium contents) parameters. PGPB has ability to make the colonies in rhizoshpere, rhizoplane or the interior of roots. Some bacteria enter the roots and perform beneficial role to the plants and some increase the surface area of the roots to easily uptake the nutrients. PGPB produce antibiotic that enhance the plant growth and development. This phenomenon shows that PGPB helps plant to improve its status of nitrogen, phosphorus, potassium, chlorophyll and relative water contents of leaf by improving uptake of essential nutrients and help crop plant to survive in water deficit conditions [19-21]. It was observed that status of plant mineral nutrient plays an important role in improving resistance against water stress condition. Inoculation of wheat seed with PGPB has positive role on leaf nitrogen, phosphorus, potassium, chlorophyll and relative water contents $[7,22]$. The conclusion made that PGPB coated fertilizer application was effective in improving the morphological and biochemical parameters of wheat in water stress condition.

\section{Authors' contributions}

Conceived and designed the experiments: A Ali \& M Tariq, Performed the experiments: M Maqbool \& A Ali, Analyzed the data: M Rashid, SA Kalhoro, Contributed materials/ analysis/ tools: MN Narejo \& FA Marri, Wrote the paper: A Ali \& M Tariq, Revise paper: M Ahmed

\section{References}

1. Passioura JB (2002). Environmental plant biology and crop improvement. Func Plant Biol 29: 537-546.

2. Wang W, Vinocur B \& Altman A (2005). Plant responses to drought, salinity and extreme temperatures towards genetic engineering for stress tolerance. Planta 218: 1-14.

3. Zahoor R, Zhao W, Abid M, Dong H \& Zhou Z (2017). Potassium application regulates nitrogen metabolism and osmotic adjustment in cotton (Gossypium hirsutum L.) functional leaf under drought stress. $J$ of Plant Physiol 215: 30-38.

4. Hoekstra PA, Golovina EA \& Buitink J (2001). Mechanisms of plant desiccation tolerance. Trends Plant Sci 6: 431-438.

5. Van B, Vranova FE, Dat FE \& Inze D (2001). The role of active oxygen species in plant signal transduction. Plant Sci 161: 403-414.

6. Ali E (2012). Effect of iron nutrient care sprayed on foliage at different physiological 412 growth stages on yield and quality of some durum wheat (Triticum durum L.) 413 varieties in sandy soil. Asian J of Crop Sci 4: 139149.

7. Singh B, Timsina $\mathrm{Y}$, Lind $\mathrm{O}$, Cagna S, \& Janssens K (2018). Zinc and Iron Concentration 426 as Affected by Nitrogen Fertilization and Their Localization in Wheat Grain. Front Plant 9: 307.

8. Hu W, Lv X, Yang J, Chen B, Zhao W, Meng Y, Wang Y, Zhou Z \& Oosterhuis DM (2016a). Effects of potassium deficiency on antioxidant metabolism related to leaf senescence in cotton (Gossypium hirsutum L.). Field Crop Res 191: 139-149.

9. Wang R, Gao M, Ji S, Wang S, Meng Y \& Zhou Z (2016). Carbon allocation, 
osmotic adjustment, antioxidant capacity and growth in cotton under long-term soil drought during flowering and boll-forming period. Plant Physiol Biochem 107: 137.

10. D'Egidio M (2012). From seed to pasta in Ethiopia: Opportunities and challenges to overcome 436 for smallholder farmers in Bale area. CRA Consiglio Perla Ricercae la Sperimentazione 437 in Agriculture, IAO.

11. Chen C, Neill K, Wichman D, \& Westcott M (2008). Hard red spring wheat response 431 to row spacing, seeding rate, and nitrogen. $J$ of Agronomy 100(432): 1296-1302.

12. Azcon R \& Barea JM (2010). Mycorrhizosphere interactions for legume improvement. Microbes for legume improvement. Vienna Springer 237-271.

13. Postma JJ, Veen AV \& Walter S (1989). Influence of different initial soil moisture contents on the distribution and population dynamics of introduced Rhizobium leguminosarum biovartrifolii. Soil Biol Biochem 21: 437-442.

14. Blum A \& Johnson JW (1992). Transfer of water from roots into dry soil and the effect on wheat water relations and growth. Plant Soil 145: 141-149.

15. Divito GA, Echeverría HE, Andrade FH \& Sadras VO (2015). Diagnosis of S deficiency in soybean crops: performance of $\mathrm{S}$ and $\mathrm{N} \quad \mathrm{S}$ determinations in leaf, shoot and seed. Field Crops Res 180: 167-175.

16. Gentry LF, Ruffo ML, Below FE (2013). Identifying factors controlling the continuous corn yield penalty. Agron J 105: 295-303.

17. Wyngaard N \& Cabrera ML (2015). Measuring and estimating sulfur mineralization potential in soils amended with poultry litter or inorganic fertilizer. Biol. Fertil. Soils 51: 545-552.

18. Chien SH, Gearhart MM \& Villagarcía S (2011). Comparison of ammonium sulfate with other nitrogen and sulfur fertilizers in increasing crop production and minimizing environmental impact: a review. Soil Sci 176: 327-335.

19. Bray EA, Bailey-Serres J \& Weretilnyk E (2000). Responses to abiotic stresses. In: W. Gruissem. B. Buchnnan and R. Jones. (Eds.). pp 1158-1249.

20. Saharan BS \& Nehra V (2011). Plant growth promoting rhizobacteria. A Critical Review. Life Sci and Med Res, pp 21.

21. Ashraf MY, Khan AH, Azmi AR (1992) Cell membrane stability and its relation with some physiological process in wheat. Acta Agron Hung 41: 183-191

22. Ryan J, Estefan G, Rashid A (2001) Soil and plant analysis laboratory manual, 2nd edn. International Center for Agriculture in Dry Areas (ICARDA), Syria. 